\title{
Trophic egg provisioning in a passalid beetle (Coleoptera)
}

\author{
$\mathrm{KYOKO} \mathrm{ENTO}^{1 *}$, Kunio ARAYA ${ }^{2}$ and SHIN-ICHI KUDO 3 \\ ${ }^{1,2}$ Graduate School of Social and Cultural Studies, Kyushu University, 4-2-1 Ropponmatsu, Chuou-ku, Fukuoka 810-8560, Japan; \\ e-mail: arayarcb@mbox.nc.kyushu-u.ac.jp \\ ${ }^{3}$ Dept of Biology, Naruto University of Education, 748, Nakashima, Takashima, Naruto-cho, Naruto City, Tokushima $772-8502$ \\ Japan; e-mail: skudo@naruto-u.ac.jp
}

Key words. Coleoptera, Passalidae, Cylindrocaulus patalis, trophic egg, parental care, subsocial

\begin{abstract}
Trophic eggs, which are not viable and eaten by larvae, are produced by the passalid beetle Cylindrocaulus patalis. This is the first record of trophic eggs in subsocial Coleoptera. There are differences in the morphology of trophic and fertile eggs; the former are a paler colour and softer than the latter. The surface of the chorion of trophic eggs is also smoother than that of fertile eggs. The trophic eggs are fed directly by the female parent to 3rd instar larvae following a series of specific behavioural interactions between them, including repeated stridulation by the larva. It is likely that trophic eggs supplement the protein-poor diet of the larvae and contribute to their growth and survival. The production of trophic eggs may be associated with the evolution of an extremely small clutch size in C. patalis.
\end{abstract}

\section{INTRODUCTION}

In insects, parental care has evolved independently in diverse taxa. In many cases, females, or sometimes males, protect their offspring against arthropod enemies (e.g., Kudo, 2002; reviewed in Tallamy \& Wood, 1986; Costa, 2006). In addition to protection, mass or progressive provisioning has also been reported; parents construct nests and feed their offspring. Although parental provisioning is well known in species of Aculeata (Hymenoptera) (Wilson, 1971) it is rare in insects in general (but see Costa, 2006, for most current review). Nutritional material supplied to offspring is sometimes parental regurgitations (e.g., in burying beetles, Scott, 1998) or parental faeces (e.g., in passalid beetles, see below). Trophic eggs can be regarded as an extreme case of a specialized food supply.

Crespi (1992) defined trophic eggs as non-developing eggs or egg-like structures produced by mothers for their offspring. They are recorded in a variety of animals, both vertebrates, such as fish, amphibians, and invertebrates, insects, spiders, spionid worms and prosobranch snails (Perry \& Roitberg, 2006). In insects, trophic egg production is often associated with eusociality; it is common in ants (Gobin et al., 1998; Cassill, 2002) and stingless bees (Koedam et al., 1996). On the other hand, there are limited records of trophic eggs in non-eusocial taxa (reviewed in Crespi, 1992; Perry \& Roitberg, 2006). In particular, trophic eggs are known in only a few subsocial species, e.g. cricket Anurogryllus muticus (Orthoptera) (West \& Alexander, 1967), shield bugs (Heteroptera), Adomerus triguttulus (Nakahira, 1994) and Parastrachia japonensis (Hironaka et al., 2005), and possibly, the pso- copteran Archipsocus gurneyi (Psocoptera) (Mockford, 1957).

Trophic eggs are thought to function as food for offspring or to reduce sibling cannibalism (Crespi, 1992), although the evolutionary process involved and ecological factors leading to it are poorly understood (Perry \& Roitberg, 2006). In non-eusocial insects, the starting point for the evolution of trophic eggs may have been sibling cannibalism of viable and those that fail to develop (Crespi, 1992). In addition, there seem to be an association between the evolution of social systems and of trophic eggs in insects (Crespi, 1992). Comparison of trophic-egg production and consumption strategies or taxa possessing different social systems and degrees of egg specialization will provide clues about the evolutionary process. New evidence on sociality-trophic-egg syndromes will certainly be useful in such analyses.

The order Coleoptera includes many subsocial species that show diverse forms of parental care (Tallamy \& Wood, 1986; Costa, 2006). Parental (mass or progressive) provisioning occurs in different coleopteran lineages, e.g., silphids (Nicrophorus, Scott, 1998), scarabaeids (Halffter, 1997), staphylinids (Bledius, Wilson, 1971), scolytids and platypodids (Kirkendall et al., 1997), and passalids (see below). Sibling cannibalism of inviable (and viable) eggs occurs in some coleopteran families (Stevens, 1992). However, trophic eggs have hitherto not been reported in subsocial taxa.

Passalidae is a family of pantropical subsocial beetles, which includes about 600 species. Most passalids live in family groups within galleries excavated in rotten logs and feed on decayed wood (Schuster \& Schuster, 1997). They breed inside the galleries. Although the composition

\footnotetext{
* Current address: Gifu World Freshwater Aquarium, 1453 Kawashimakasadamachi, Kakamigahara City, Gifu 500-6021, Japan; e-mail: k-ento@aquatotto.co.jp
} 
of the colonies differ among species, the most common is a male and female cohabitating with offspring. Passalid beetles show complex parental care (Schuster \& Schuster, 1997), including sophisticated feeding behaviour. The larvae feed not only on wood chewed by adults but also on their faeces (Valenzuela-Gonzalez, 1992). The mandibles of larvae do not appear to be strong enough to chew wood from the gallery wall (Reyes-Castillo \& Jarman, 1981). In addition, the larvae need the nitrogen in the faeces of their parents for growth (Valenzuela-Gonzalez, 1984) and thus, sometimes cannot survive unless cared for by their parents (Valenzuela-Gonzalez, 1992). Passalid beetles show one of the closest associations between parents and offspring in Coleoptera (Araya et al., 1996).

In this paper, the production and consumption of specialized trophic eggs in the passalid beetle Cylindrocaulus patalis (Lewis, 1883) are described. This is the first report of parental provisioning of trophic eggs in subsocial Coleoptera.

\section{MATERIAL AND METHODS}

\section{Insects}

In Japan, an endemic species of Passalidae, C. patalis, subfamily Aulacocyclinae, is known to exist in the southwestern regions, Shikoku and Kyushu, at elevations of over $1000 \mathrm{~m}$ in the mountains (Miyatake, 1959). C. patalis lives in family groups in galleries in rotten wood, which are about $20 \mathrm{~cm}$ long and have branches. Adults are active from April to October and hibernate from December to March. Colonies usually include a male and female. The breeding season lasts from June to August, the hottest time of the year. Only a single adult is raised per colony per year (Ento et al., 2003). It is thought that $C$. patalis lives at least two years and reproduces more than twice during its lifetime. The parents defend their offspring against intruders, feed them with chewed wood and assist them in the construction of pupal cases (Ento, 2005). Larvae often use their degenerate hind legs to stridulate when receiving parental care which is essential for their survival. Newly emerged adults often stay with their parents until the following spring and some even until the next breeding season (Ento, 2005).

\section{Study site}

Fifteen colonies containing two adults and eggs, and nine containing one larva and two adults were collected in June in the cool temperate zone at Mt. Shiraiwa, Gokase-cho, Nishiusuki-gun, Miyazaki Prefecture, southwest Japan $\left(32^{\circ} 35^{\prime} \mathrm{N}, 131^{\circ} 7^{\prime} \mathrm{E}, 1400-1580 \mathrm{~m}\right.$ in altitude). This area is dominated by broad-leaved trees, such as Japanese beech (Fagus crenata) and Japanese oak (Quercus serrata), which provide a dense cover of litter. Rotten trees were cut open by hand axe until the terminals of a colony gallery system were reached and all individuals in the colony were collected. The composition of colonies collected for subsequent rearing (number of colonies) was as follows: a pair and one egg (five) in 2001; a pair and one egg (four), a pair and four eggs (one), a pair and one larva (nine) in 2002; a pair and two eggs (two), and a pair and three eggs (three) in 2003.

\section{Rearing}

The rearing for direct observation took place from June to August in 2001, 2002 and 2003. The field-collected colonies were brought into the laboratory and reared in plastic Petri dishes ( $80 \mathrm{~mm}$ dia., $13 \mathrm{~mm}$ ht.) filled with small pieces of wood for food. The rearing Petri dishes were kept continuously in the dark in an incubator (MRI-153, SANYO), in which the temperature varied between 15 and $20^{\circ} \mathrm{C}$. These temperatures correspond approximately with the average gallery temperature recorded in the field during the breeding season (Ento et al., 2003). The egg period lasts for approximately five weeks under such conditions (Ento, 2005). The small pieces of wood in the Petri dishes were moistened every five days, and cleaned or exchanged every two weeks (Ento \& Araya, 2003). Since the adults of $C$. patalis are not sexually dimorphic in their external morphology, an individual in each adult pair was marked on its elytra with a white waterproof pen for individual discrimination. Dissection after rearing revealed that the two adults in a colony were invariably a male and female.

\section{Behavioural observations}

We observed 15 colonies that contained larvae and adults in 2001, 2002 and 2003. The colonies that had eggs were observed after the eggs hatched. Observations are made on three days in each week from mid-June to early August, from 19:00 for two to four hours. One colony was selected randomly to be observed on each day. The investigation lasted until the larvae pupated. Total observation time was $252 \mathrm{~h} ; 60 \mathrm{~h}$ in 2001, $100 \mathrm{~h}$ in 2002 and $92 \mathrm{~h}$ in 2003, respectively. The time spent recording the behaviour of particular larval instars was: $164 \mathrm{~h}$ for first and second instar larvae and $88 \mathrm{~h}$ for third, final instar larvae.

To minimize the disturbance of colony members, the following video camera and illumination systems for night viewing were used: CCD Camera (WAT-902H, WATEC) and CCTV Lens (TS 412A, PENTAX), Video Camera (Hi8 CCD-TR11, SONY) with infrared light (IRL-C4-170-880, HOGA), Digital Video Camera (DCR-PC2NT3C, SONY) with flashlight covered with red film and Digital Video Camera with NightShot function (DCR-TRV33K, SONY).

\section{Examination of eggs}

Another nine colonies containing larvae and adults were also reared to collect the egg-like material (trophic eggs). When females deposited trophic eggs (see the results) they were immediately collected. A total of 12 trophic eggs were collected. Three were kept moist in Petri dishes to confirm whether they developed, and the remaining nine preserved in $70 \%$ ethanol. Three fertile eggs and an egg shell that remained after hatching were collected from colonies in the field and preserved in $70 \%$ ethanol. The length and width of the trophic eggs and fertile eggs were measured under a stereoscopic microscope using an ocular micrometer. Fertile eggs increase in volume due to water absorption during embryonic development (Ento, 2005). We were unable to determine the day when the fertile eggs were laid, so the size of the fertile eggs was not used in the subsequent analysis. Hatchability of fertile eggs is high, approximately $90 \%$ (Ento, unpubl. data).

The surface structure of the trophic and fertile eggs was examined under a scanning electron microscope (JSM-5600LV, JEOL). Before the examination, trophic and fertile eggs were dehydrated through a series of increasing concentrations of ethanol and then placed in $100 \%$ t-butyl alcohol (Inoue \& Osatake, 1988). After this treatment, they were dried in a freeze drying machine (JFD-300, JEOL). A piece of cut cover-glass was then mounted on a metal stub using double-sided adhesive tape and edged with conductive paint (Dotite type D-550). The material was attached to the cover-glass with water soluble glue. They were gold coated four times for some minutes each using an ion sputtering system (JSM-35, JEOL). 

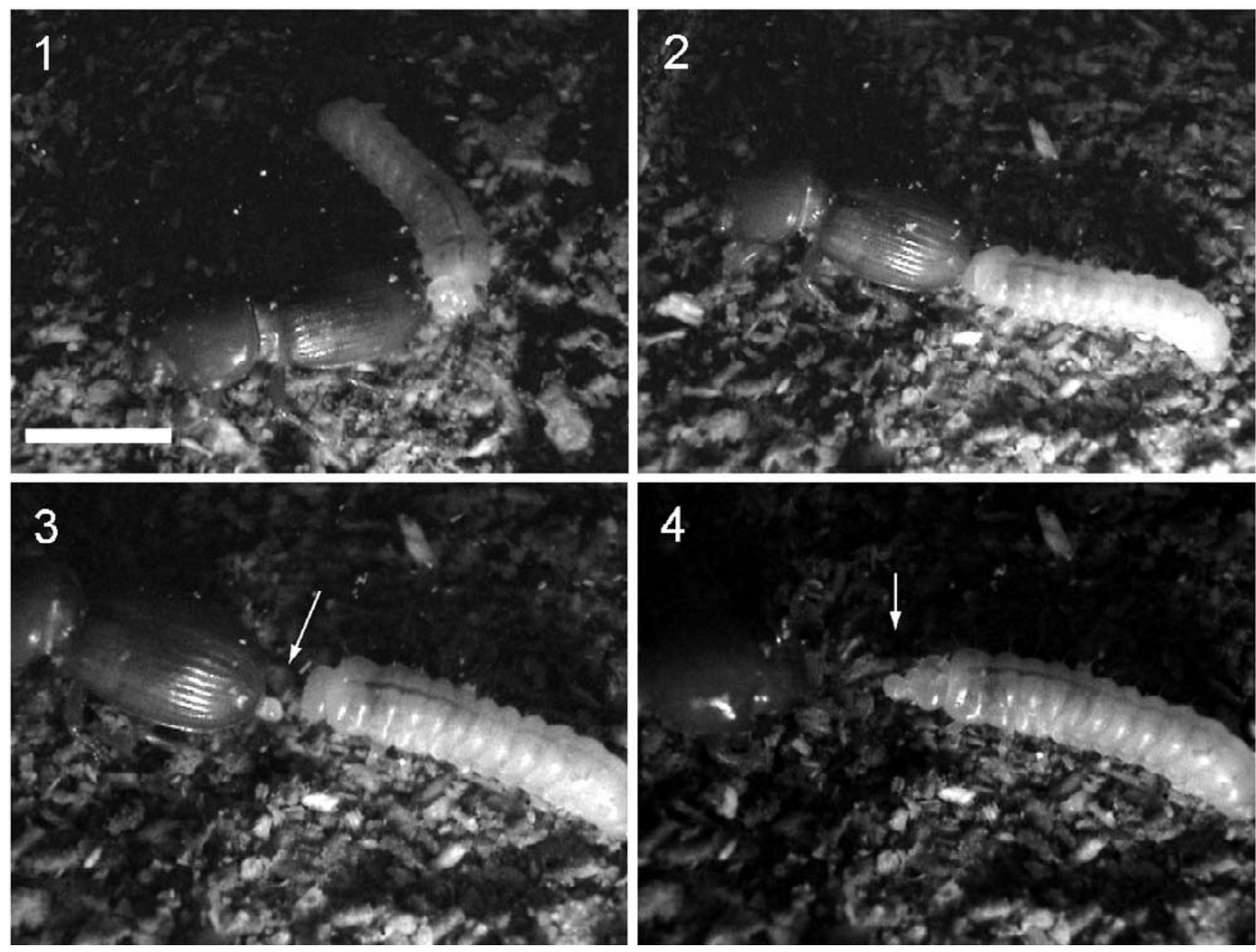

Fig. 1. The typical behavioural sequence shown by parents feeding larvae with trophic eggs. A larva encounters a female parent (1). The larva pushes its head against the female's tail (2). The female moves forward and lays a single trophic egg (3). The larva eats trophic egg while the female directs her head towards the larva (4). The scale indicates $1.0 \mathrm{~mm}$. The arrows indicate the trophic eggs.

\section{RESULTS}

\section{Feeding behaviour}

In 13 of 15 colonies, a single larva developed to the $3 \mathrm{rd}$ instar and successfully pupated, but in the remaining two colonies the larva died before pupation. It was observed that females fed their 3rd instar larvae with trophic eggs they produced from their cloaca (Fig. 1), but not their 1st or 2 nd instar larvae. The typical behavioural sequence was as follows. When a larva encountered a female, the larva rubbed and pressed its head against her body (Fig. 1-1). The female turned her tail towards the larva which touched the posterior margin of the female's elytra with its head. They stayed in tandem for several minutes (Fig. 1-2), after which the female walked forward and deposited a trophic egg in front of the larva (Fig. 1-3), which found and ate it immediately. The female turned her head towards the larva and maintained physical contact with the area around the mandibles of the larva with her antennae during the eating (Fig. 1-4). During feeding, the larvae stridulated repeatedly with their hind legs.

Feeding on trophic eggs was recorded eight times in three colonies (three 3rd instar larvae) during observations in 2003. Invariably, only one trophic egg was given to a larva during a feeding event, and the maximum number recorded provided to an individual larva was three. The production of trophic eggs was not always observed after encounters between females and larvae; in fact, females often neglect the larvae. However, when provided, trophic eggs were always eaten.

\section{Characteristics of trophic eggs}

No trophic egg kept in a Petri dish increased in volume, suggesting they do not absorb water. They did not hatch, even after two months. The trophic eggs were round and light beige in colour (Fig. 2-1), while fertile eggs are oval and brown in colour (Fig. 2-2) and the former softer than the latter. The size of a trophic egg was, on average, 1.41 \pm 0.12 (SD) $\mathrm{mm}$ in length and $1.30 \pm 0.14 \mathrm{~mm}$ in width $(\mathrm{N}$ $=9)$. The SEM observations revealed that the surface of the trophic eggs was covered with a meshwork and smooth swellings (Fig. 2-3), while that of fertile eggs as covered with honeycomb-like depressions (Fig. 2-4), which were not seen on the surface of the former.

Two females that attended 3rd instar larvae were dissected. In their ovaries, each of which consisted of two ovarioles, there were seven or eight trophic eggs (Fig. 3), 

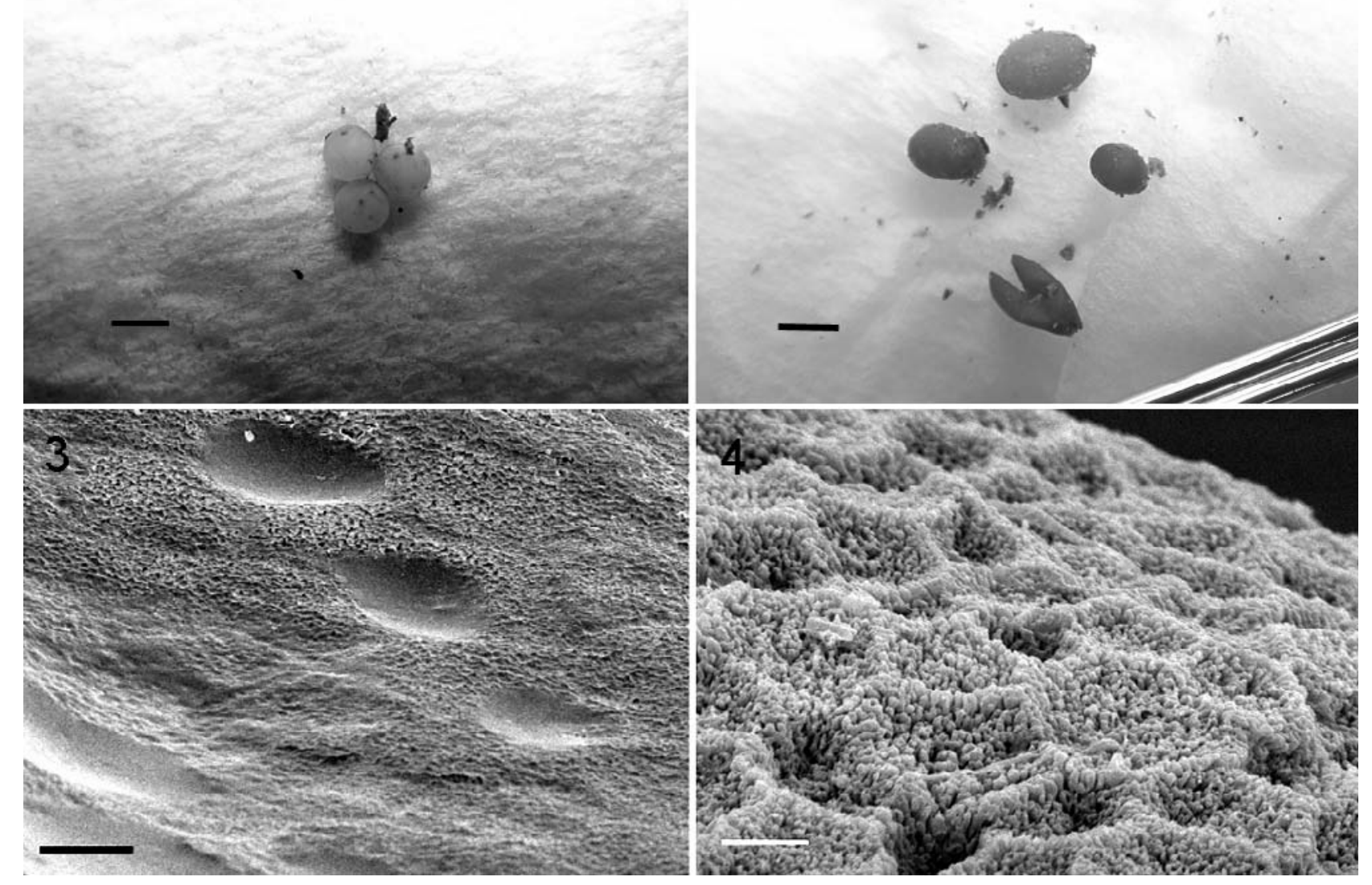

Fig. 2. Trophic (1) and viable egg (2). The scale indicates $1.0 \mathrm{~mm}$. The surface microstructure of a trophic egg (3) and viable egg (4). The scale indicates $10.0 \mu \mathrm{m}$.

which were round and light beige in colour, similar to those fed to larvae.

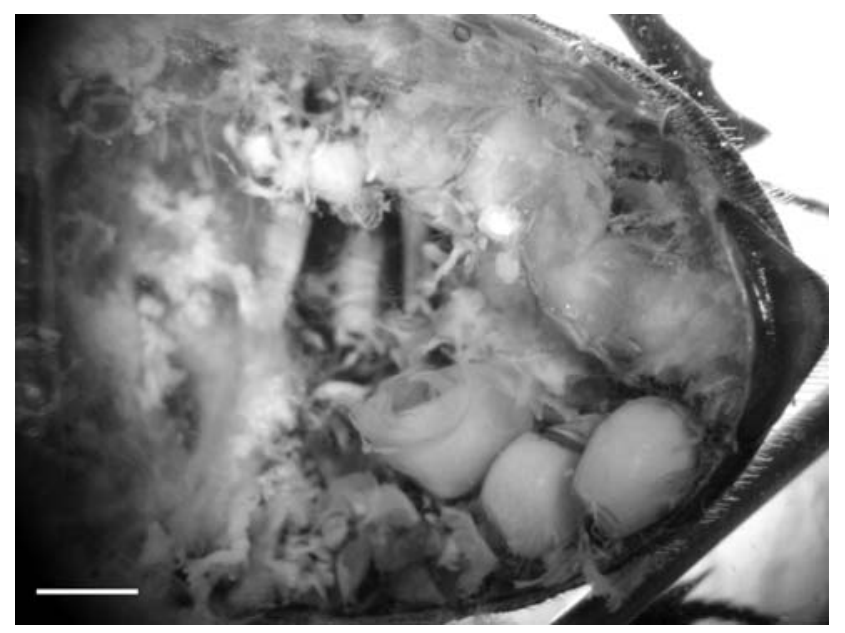

Fig. 3. Ovaries containing eight trophic eggs. Some ovarioles have been removed. The scale indicates $1.0 \mathrm{~mm}$.

\section{DISCUSSION}

The trophic eggs produced by female parents were infertile and always eaten by larvae. This indicates that the trophic eggs produced by $C$. patalis are utilized by larvae as food. These eggs satisfy Crespi's (1992) definition of trophic eggs, namely "ovarian-derived structures or fluid, homologous to fertile eggs that cannot develop into viable offspring and are normally eaten". In addition, there were differences in the colour and chorion surface structure of trophic and fertile eggs, and female parents showed specialized trophic egg delivery behaviour, i.e., direct feeding of larvae. This indicates that the trophic eggs are not simply failed byproducts (Perry \& Roitberg, 2006). Although parental feeding of larvae with chewed wood and faeces is reported in many species of Passalidae (reviewed in Schuster \& Schuster, 1997), this is the first report of trophic egg production and provisioning in this subsocial taxon. In C. patalis, it was not easy to confirm the production of trophic eggs because they are consumed immediately on deposition. Direct and sequential monitoring of the behavioural interactions between the parents and larvae in other species is needed to determine the extent of trophic-egg provisioning in Passalidae. 
Trophic eggs are expected to be less costly than viable eggs for females to produce and for offspring to consume (Crespi, 1992). Such specialization may be reflected in their morphology. It is often reported that trophic eggs in eusocial insects are flaccid or lack a chorion (e.g., ants, Passera et al., 1968; Gobin et al., 1998; stingless bees, Koedam et al., 1996). This is also the case for $C$. patalis trophic eggs; a soft chorion would make it easier for larvae that possess less developed mandibles to consume the egg contents as well reduce the material cost of oogenesis. The smoother surface of the trophic egg chorion may also indicate a lower production cost.

Trophic eggs are often smaller than fertile eggs (e.g., West \& Alexander, 1967; Gobin et al., 1998; Hironaka et al., 2005) and sometimes lack micropyles (e.g., Henry, 1972; Koedam et al., 1996; Gobin et al., 1998; Kudo et al., 2006). In some ant species, there are chemical differences between the contents of trophic and viable eggs (Wheeler, 1994). It is unknown whether this is the case in C. patalis.

The behavioural observations and dissections of females revealed that $C$. patalis females provide their $3 \mathrm{rd}$ instar larvae with several trophic eggs. The nutritional advantages of feeding trophic eggs to offspring have been quantified in a few non-social insects (e.g., Kudo \& Nakahira, 2004; Hironaka et al., 2005). It is most likely that in C. patalis, trophic egg feeding also contributes to larval growth and/or survival.

Because their food is so poor in nitrogen one of the most serious problems for xylophagous insects is obtaining sufficient nitrogen for growth (ValenzuelaGonzalez, 1992; Araya et al., 1996). In xylophagous insects, larvae often eat the faeces of their parents, which are rich in protein (Valenzuela-Gonzalez, 1992; Park \& Choe, 2003). Such protein-rich supplements accelerate the growth of the offspring (Schuster \& Schuster, 1997; Park \& Choe, 2003). In C. patalis, trophic eggs may be an important protein source for the development of final instar larvae. Interestingly, feeding on faeces occurs infrequently in $C$. patalis (Ento, 2005). It is possible that in $C$. patalis trophic eggs rather than parental faeces provide the protein needed by final instar larvae before pupation. When evaluating the nutritional economy of different protein sources, parental faeces and trophic eggs will be an interesting subject for future research.

Trophic egg production potentially imposes direct costs on females: namely a reduction in clutch size. The clutch size of $C$. patalis is extremely small; females lay less than five eggs, often only one, and raise a single adult in each breeding season (Ento et al., 2003; Ento, 2005). If the low fecundity in this species is advantageous compared to the high fecundity in other passalids (Schuster \& Schuster, 1997), it may affect the cost of trophic egg production. The evolution of trophic eggs in C. patalis is presumably associated with the extremely small clutch size.

In $C$. patalis, the trophic eggs were fed to larvae directly by female parents after they were subjected to head-rubbing by the larvae. Furthermore, as is reported in other passalids (Schuster \& Schuster, 1997), C. patalis larvae stridulate by rubbing their reduced hind legs against the coxae of their mid-legs (Ento, 2005). It is likely that head-rubbing and stridulation signal the solicitation of parents by offspring, like begging by burying beetle larvae (Rauter \& Moore, 1999). This system will provide a good opportunity for testing theories in evolutionary ecology on conflict among family members, e.g., the honest signalling model (Godfray, 1991), as well as parental care.

ACKNOWLEDGEMENTS. We express our thanks to M. Kon of the University of Shiga Prefecture for valuable advice, and $\mathrm{H}$. Shima and O. Yata of Kyushu University for guidance and encouragement. We wish to thank the members of Biosystematics Laboratory Graduate School of Social and Cultural Studies for their assistance in the field and useful advice. Comments from anonymous reviewers improved the manuscript. This study was partially supported by a Sasakawa Scientific Research Grant from The Japan Science Society and a Grantin-Aid for Scientific Research (C: 13640628) from the Japan Society for the Promotion of Science.

\section{REFERENCES}

Araya K., Kon M. \& Ueda A. 1996: Subsociality in woodeating beetles. In Saitou Y. (eds): The Evolutionary Ecology of Parent-offspring Relations. Hokkaido University Press, Sapporo, pp. 74-108 [in Japanese].

CAssill D. 2002: Brood care strategies by newly mated monogyne Solenopsis invicta (Hymenoptera: Formicidae) queens during colony founding. Ann. Entomol. Soc. Am. 95: 208-212.

Costa J. 2006: The Other Insect Societies. Belknap Press of Harvard University Press, Cambridge, MA, 767 pp.

CRESPI B.J. 1992: Cannibalism and trophic eggs in subsocial and eusocial insects. In Elgar M.A. \& Crespi B.J. (eds): Cannibalism: Ecology and Evolution among Diverse Taxa. Oxford University Press, Oxford, pp. 176-213.

EnTo K. 2005: Studies on the Natural History of Cylindrocaulus patalis (Coleoptera: Passalidae). PhD Thesis. Kyushu University, Fukuoka, Japan, 48 pp.

Ento K. \& Araya K. 2003: Rearing method of Cylindrocaulus patalis using the plastic petri dishes. The Nature and Insects 38: 25-28 [in Japanese].

Ento K., Araya K. \& Kon M. 2003: The life history and colony composition of Cylindrocaulus patalis (Coleoptera: Passalidae). Sociobiology 42: 795-806.

Gobin B., Peeters C. \& Billen J. 1998: Production of trophic eggs by virgin workers in the ponerine ant Gnamptogenys menadensis. Physiol. Entomol. 23: 329-336.

Godfray H.C.J. 1991: Signalling of need by offspring to their parents. Nature 352: 328-330.

HALFFTER G. 1997: Subsocial behaviour in Scarabaeinae beetles. In Choe J.C. \& Crespi B.J. (eds): The Evolution of Social Behavior in Insects and Arachnids. Cambridge University Press, Cambridge, pp. 237-259.

HENRY C.S. 1972: Eggs and repagula of Ululodes and Ascaloptynx (Neuroptera: Ascalaphidae): a comparative study. Psyche 79: 1-22.

Hironaka M., Nomakuchi S., Iwakuma S. \& Filippi L. 2005: Trophic egg production in a subsocial shield bug, Parastrachia japonensis Scott (Heteroptera: Parastrachiidae), and its functional value. Ethology 111: 1089-1102.

Inoue T. \& Osatake H. 1988: An epoch-making specimendrying method superceding a critical point drying one. Archiv. Histol. Cytol. 51: 53-59. 
Kirkendall L.A., Kent D.S. \& RafFa K.F. 1997: Interactions among males, females and offspring in bark and ambrosia beetles: the significance of living in tunnels for the evolution of social behavior. In Choe J.C. \& Crespi B.J. (eds): The Evolution of Social Behavior in Insects and Arachnids. Cambridge University Press, Cambridge, pp. 181-215.

Koedam D., Velthausz P.H., Krift T. van der, Dohmen M.R. \& SOMMEIJER M.J. 1996: Morphology of reproductive and trophic eggs and their controlled release by workers in Trigona (Tetragonisca) angustula Illiger (Apidae, Meliponinae). Physiol. Entomol. 21: 289-296.

Kudo S. 2002: Phenotypic selection and function of reproductive behavior in the subsocial bug Elasmucha putoni (Heteroptera: Acanthosomatidae). Behav. Ecol. 13: 742-749.

KudO S. \& NAKAHIRA T. 2004: Effects of trophic-eggs on offspring performance and rivalry in a sub-social bug. Oikos 107: 28-35.

Kudo S., Nakahira T. \& Saito Y. 2006: Morphology of trophic eggs and ovarian dynamics in the subsocial bug Adomerus triguttulus (Heteroptera: Cydnidae). Can. J. Zool. 84: 723-728.

Miyatake M. 1959: The life of Cylindrocaulus patalis. In Iwata K., Hurukawa H. \& Yasumatsu K. (eds): Nihon Kontyuuki (An Account of Japanese Insects) 5. Koudansya, Tokyo, pp. 206-234 [in Japanese].

Mockford E.L. 1957: Life history studies on some Florida insects of the genus Archipsocus (Psocoptera). Bull. Florida State Mus. 1: 253-274.

NaKahiRa T. 1994: Production of trophic eggs in the subsocial burrower bug Admerus triguttulus. Naturwissenschaften 81: 413-414.

PARK Y.C. \& ChOE J.C. 2003: Effects of parental care on offspring growth in the Korean wood-feeding cockroach, Cryptocercus kyebangensis. J. Ethol. 21: 71-77.

Passera L., Bitsch J. \& BressaC C. 1968: Observations histologiques sur la formation des oeufs reproducteurs chez les ouvrieres de Plagiolepis pygmaea Latr. (Hymenoptera Formicidae). C. R. Acad. Sci. (Paris) (D) 266: 2270-2272.
Perry J.C. \& Roitberg B.D. 2006: Trophic egg laying: hypotheses and tests. Oikos 112: 706-714.

Rauter C.M. \& Moore A.J. 1999: Do honest signalling models of offspring solicitation apply to insects? Proc. R. Soc. Lond. (B) 266: 1691-1696.

Reyes-Castillo P. \& Jarman M. 1981: Estudio comparativo de la fuerza ejercida por las mandíbulas de larva y adulto de Passalidae (Coleoptera: Lamellicornia). Folia Entomol. Mex. 48: 97-99.

Schuster J.C. \& Shuster L.B. 1997: The evolution of social behavior in Passalidae (Coleoptera). In Choe J.C. \& Crespi B.J. (eds): The Evolution of Social Behavior in Insects and Arachnids. Cambridge University Press, Cambridge, pp. 260-269.

Sсотт M.P. 1998: The ecology and behavior of burying beetles. Annu. Rev. Entomol. 43: 595-618.

Stevens L. 1992: Cannibalism in beetles. In Elgar M.A. \& Crespi B.J. (eds): Cannibalism: Ecology and Evolution among Diverse Taxa. Oxford University Press, Oxford, pp. 156-175.

Tallamy D.W. \& Wood T.K. 1986: Convergence patterns in subsocial insects. Annu. Rev. Entomol. 31: 369-390.

Valenzuela-Gonzalez J.E. 1984: Contribution à l'etude du comportement des Passalidae (Coleoptera, Passalidae). Thesis, Univ. Paris XIII, 112 pp.

Valenzuela-Gonzalez J.E. 1992: Adult-juvenile alimentary relationships in Passalidae (Coleoptera). Folia Entomol. Mex. 85: $25-37$.

West M.J. \& AleXander R.D. 1967: Subsocial behavior in a burrowing cricket Anurogryllus muticus (De Geer). Ohio J. Sci. 63: 19-24.

WHEELER D.E. 1994: Nourishment in ants: patterns in individuals and societies. In Hunt J.H. \& Nalepa C.A. (eds): Nourishment and Evolution in Insect Societies. Westview, Boulder, Colorado, pp. 245-278.

Wilson E.O. 1971: The Insect Societies. Belknap Press of Harvard University Press, Cambridge, MA, 548 pp.

Received March 6, 2007; revised and accepted August 27, 2007 